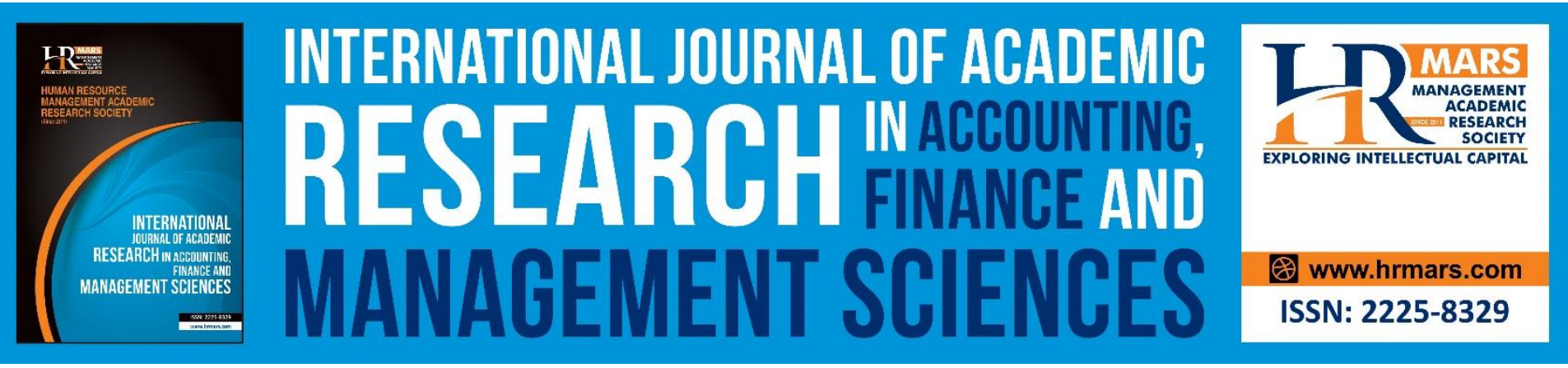

\title{
The TOPSIS with Distance Score Function of Hesitant Fuzzy Sets in Investment Selection
}

Putrizatul Ain Mohamad Radzib, Syifa Syuhada Razali, Anis Firdaus Sarudin, Zahari Md Rodzi

To Link this Article: http://dx.doi.org/10.6007/IJARAFMS/v11-i2/10057 $\quad$ DOI:10.6007/IJARAFMS /v11-i2/10057

Received: 18 April 2021, Revised: 20 May 2021, Accepted: 07 June 2021

Published Online: 26 June 2021

In-Text Citation: (Radzib et al., 2021)

To Cite this Article: Radzib, P. A. M., Razali, S. S., Sarudin, A. F., \& Rodzi, Z. M. (2021). The TOPSIS with Distance Score Function of Hesitant Fuzzy Sets in Investment Selection. International Journal of Academic Research in Accounting Finance and Management Sciences, 11(2), 150-157.

\section{Copyright: (c) 2021 The Author(s)}

Published by Human Resource Management Academic Research Society (www.hrmars.com)

This article is published under the Creative Commons Attribution (CC BY 4.0) license. Anyone may reproduce, distribute, translate and create derivative works of this article (for both commercial and non-commercial purposes), subject to full attribution to the original publication and authors. The full terms of this license may be seen

at: http://creativecommons.org/licences/by/4.0/legalcode

\section{Vol. 11, No. 2, 2021, Pg. 150 - 157}

Full Terms \& Conditions of access and use can be found at http://hrmars.com/index.php/pages/detail/publication-ethics 


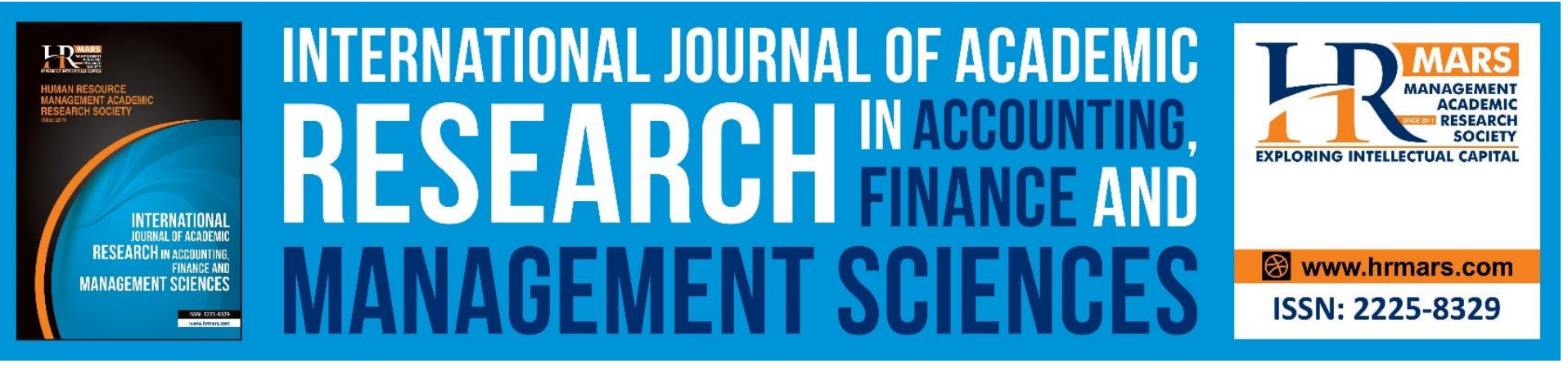

\title{
The TOPSIS with Distance Score Function of Hesitant Fuzzy Sets in Investment Selection
}

\author{
Putrizatul Ain Mohamad Radzib, Syifa Syuhada Razali, Anis Firdaus \\ Sarudin, Zahari Md Rodzi \\ Faculty of Computer and Mathematical Sciences, Universiti Teknologi MARA Cawangan Negeri \\ Sembilan, Kampus Seremban, Malaysia \\ Email: zahari@uitm.edu.my
}

\begin{abstract}
The hesitant fuzzy set (HFS) concept is a highly effective tool for dealing with uncertain data. Indeed, the latter approach allows for the representation of an attribute's membership degree in a given set as a range of possible numerical values between $[0,1]$. In practise, the length of the hesitant fuzzy element varies. Certain methods include adding elements to a shorter hesitant fuzzy element, equating it to another hesitant fuzzy element, or repeating their elements in order to obtain two series of equal length. Clearly, these methods will destroy the original data structure and modify the data. To cater this problem, we proposed a new distance method in this paper based on the score function (arithmetic-mean, geometric-mean, product, and fractional) in the ideal solution of technique for order of preference by similarity to ideal solution (TOPSIS) in the HFS environment. Then, we apply the proposed method of distance score function for selecting an investment portfolio in multi-criteria decision making (MCDM) problem. Finally, a numerical example of investment portfolio decision making in a hesitant fuzzy environment is used to demonstrate their benefits and feasibility. To validate the proposed approach, a comparison with other methods is presented; the results are consistent, demonstrating that this technique is faster and more effective in practical applications.
\end{abstract}

Keywords: Hesitant Fuzzy Set, Score Function, Arithmetic-Mean, Geometric Mean, Fractional, TOPSIS.

\section{Introduction}

Multiple criteria decision making (MCDM) is a technique for making decisions when multiple, primarily difficult, criteria are present. The researcher is utilising MCDM to address the issue at hand. The MCDM method has been widely used in a variety of situations to determine the most appropriate choice, TOPSIS method.

The TOPSIS method is a decision-making technique that enables the optimal selection of alternatives based on a variety of criteria. Hwang and Yoon invented it in 1981. This method can be 
INTERNATIONAL JOURNAL OF ACADEMIC RESEARCH IN ACCOUNTING, FINANCE AND MANAGEMENT SCIENCES

Vol. 11, No. 2, 2021, E-ISSN: 2225-8329 @ 2021 HRMARS

applied to everyday problems as well as scientific research. When using this method, the selected alternative is expected to be close to the ideal solution and far from the negative ideal solution. If financial return is a consideration, proximity to the ideal solution equates to maximisation of return, while distance from the negative ideal solution equates to cost minimization. While the desired alternative should be close to the ideal solution, it should be as far away from the negative ideal solution.as possible. Among the alternatives, the one closest to the ideal solution is chosen, followed by the one furthest from the negative ideal solution.

Ece and Uludag (2017) proposed applicability of fuzzy topsis method in optimal portfolio selection and an application in BIST. While, Huang and Jiang (2018) introduced the Extension of TOPSIS method and its application in investment. Moayyed et al (2019) identifying the factors affecting manufacturing investment projects and using TOPSIS method for prioritizing projects. Ozyesil (2019) proposed an application of TOPSIS method for financial decision making process and any other applications of TOPSIS (Beg \& Rashid, 2016; Mishra et al., 2019; Rodzi \& Ahmad, 2020; Xu \& Zhang, 2015)

However, the problem in the real world is complicated because it includes people, technology, machinery, economics, the environment, and a variety of management fields. As a result, they can be classified as ambiguity, vagueness, or imprecision. According to Rodriguez, Matinez, Torra, $\mathrm{Xu}$, and Herrera (2014), uncertainty can take many forms, including fuzziness, incompleteness, indistinguishability, and randomness.

Vicenc Torra (2010); Vicenç Torra \& Narukawa (2009) pioneered the hesitant fuzzy set concept. Hesitant fuzzy sets exhibit a degree of membership value that ranges from zero to one. This can be seen in instances where the researcher expresses reluctance to provide a reference to the research objective during the decision-making process. The hesitant fuzzy set theory is a new extension of the traditional fuzzy set theory. It was introduced to address situations characterised by a hesitant state. A hesitant fuzzy set is developing from an intuitionistic fuzzy set.

It should be noted that current research on the operation, sorting, and various measures of hesitant fuzzy sets requires that the hesitant fuzzy elements be identical in length. In practice, the length of the hesitant fuzzy element varies. The method proposed in Xu and Xia (2011) entails adding some elements to a shorter hesitant fuzzy element, equating it to another hesitant fuzzy element, or repeating their elements to obtain two series of equal length (Garmendia et al., 2017). Clearly, these methods will destroy the original data structure and modify the data. How to overcome the shortcomings has become a pressing issue in the process of developing hesitant fuzzy sets?

Our work is organized as follows. Section 2 summarizes some fundamental definitions of HFS and HFE score functions. Section 3 will discuss TOPSIS in conjunction with HFS's distance score functions. Section 4 details the investment selection used to demonstrate our algorithm's efficacy. Finally, Section 5 makes some concluding remarks and suggests areas for future research.

\section{Prelimanaries}

This section is dedicated to explaining the definitions relating to HFS and score functions of HFE.

Definition 1 (Xia \& Xu 2011) Allow for a fixed set $X$. Then, in terms of a function $h$, a hesitant fuzzy set (HFS) on $X$ is one that, when applied to $H$, returns a subset of $[0,1]$. To make their point clear, $\mathrm{Xu}$ and Xia expressed the hesitant fuzzy set by the following manner. 
INTERNATIONAL JOURNAL OF ACADEMIC RESEARCH IN ACCOUNTING, FINANCE AND MANAGEMENT SCIENCES

Vol. 11, No. 2, 2021, E-ISSN: 2225-8329 @ 2021 HRMARS

$$
\left.H=\left\{x, \tilde{h}_{A}(x)\right): x \in X\right\}
$$

where $h_{A}(x)$ is a collection of distinct values in the range $[0,1]$ referred to as hesitant fuzzy elements (HFEs), which represent the possible degrees of membership of the element $x \in X$ to $A$.

Definition 2 (Farhadinia 2014) Assume $\tilde{h}=\left(h_{1}, h_{2}, \ldots, h_{n}\right)$ is an HFE. The following functions can be used to calculate the score for HFEs:

1. The arithmetic-mean score function

$$
s_{A M}(\tilde{h})=\frac{1}{n} \sum_{1=i}^{n} h_{i}
$$

2. The geometric-mean score function:

$$
s_{G M}(\tilde{h})=\left(\prod_{1=i}^{n}\left(h_{i}\right)\right)^{\frac{1}{n}}
$$

3. The product score function

$$
s_{p}(\tilde{h})=\prod_{1=i}^{n} h_{i}
$$

4. The fractional score function

$$
s_{F}(\tilde{h})=\frac{\prod_{1=i}^{n} h_{i}}{\prod_{1=i}^{n} h_{i}+\prod_{1=i}^{n}\left(1-h_{i}\right)}
$$

\section{TOPSIS with distance score functions in HFS}

We propose the TOPSIS method with a distance score measure for multiple attribute group decision making using HFS information in this section. TOPSIS is a technique for identifying solutions from a finite collection of possibilities by Hwang and Yoon (1981). Alternative solutions should be as close to the positive ideal solution as possible, while being as far away from the negative ideal solution as possible. The TOPSIS algorithm for computing the HFS distance score is depicted in Figure 1.

\begin{tabular}{|l|l|}
\hline - Set up HFS decision matrix \\
\hline $\begin{array}{l}\text { - Find the score matrix } \\
\text { - Find the distance from positive and negative ideal } \\
\text { solution }\end{array}$ \\
\hline Step 1
\end{tabular}

Figure 1. TOPSIS with different score functions and ideal solution. 
INTERNATIONAL JOURNAL OF ACADEMIC RESEARCH IN ACCOUNTING, FINANCE AND

MANAGEMENT SCIENCES

Vol. 11, No. 2, 2021, E-ISSN: 2225-8329 @ 2021 HRMARS

Step 1. Form the HFS decision matrix.

Step 2. Calculate the score for the HFS element such as in Definition 2.

Step 3. Establish both the positive ideal solution (PIS) and the negative ideal solution (NIS).

$s\left(\tilde{h}_{j}\right)^{+}= \begin{cases}\max _{i} s\left(\tilde{h}_{i j}\right) & \text { benefit criteria } \\ \min _{i} s\left(\tilde{h}_{i j}\right) & \text { cost criteria }\end{cases}$

and

$s\left(\tilde{h}_{j}\right)^{-}= \begin{cases}\min _{i} s\left(\tilde{h}_{i j}\right) & \text { benefit criteria } \\ \max _{i} s\left(\tilde{h}_{i j}\right) & \text { cost criteria }\end{cases}$

Step 4. Calculate the distance between PIS and NIS against the value of the Z-score.

$$
\begin{aligned}
& d_{i}^{+}=\sqrt{\sum_{j=1}^{n}\left(s\left(\tilde{h}_{j}\right)^{+}-s\left(\tilde{h}_{i j}\right)\right)^{2}} \quad, i=1,2, \ldots, n \\
& d_{i}^{-}=\sqrt{\sum_{j=1}^{n}\left(s\left(\tilde{h}_{i j}\right)-s\left(\tilde{h}_{j}\right)^{-}\right)^{2}} \quad, i=1,2, \ldots, n
\end{aligned}
$$

Step 5. Calculate the value of the coefficient index, for each alternative

$$
C l_{i}=\frac{d_{i}^{-}}{d_{i}^{-}+d_{i}^{+}}
$$

Step 6. Establish a ranking order based on values and select the best alternative.

\section{Applications of Investment Selection}

There is an investment firm that wishes to make the best possible investment company (adapted from (Beg \& Rashid 2017). Five possible investments include the following: $A 1$ represents the automobile company, $A 2$ represents the food company, $A 3$ represents the computer company, $A 4$ represents the defense company, and $A 5$ represents the television company. The investment company must make a determination based on the four criteria listed below: $C 1$ is an analysis of risk; C2 is an analysis of growth; C3 is an analysis of social-political impact; and C4 is an analysis of environmental impact. The decision will be made by the board of directors of the company. Table 1 and Table 2 show the alternatives involved and criteria description of this selection respectively.

Table 1. Investment industries

\begin{tabular}{cc}
\hline Item & Alternative \\
\hline Alternative $1(A 1)$ & Car company \\
Alternative 2 $(A 2)$ & Food company \\
Alternative $3(A 3)$ & Computer company \\
Alternative 4 (A4) & Arms company \\
Alternative 5 (A5) & Television company \\
\hline
\end{tabular}


INTERNATIONAL JOURNAL OF ACADEMIC RESEARCH IN ACCOUNTING, FINANCE AND MANAGEMENT SCIENCES

Vol. 11, No. 2, 2021, E-ISSN: 2225-8329 @ 2021 HRMARS

Table 2. Description of criteria

\begin{tabular}{cll}
\hline \multicolumn{1}{c}{ Item } & Criteria & Description \\
\hline Criteria 1 (C1) & The analysis of risk & $\begin{array}{l}\text { To reduce uncertainty risk happen } \\
\text { want to make the investment to the } \\
\text { alternative. High risk will give profit } \\
\text { more, vice versa. }\end{array}$ \\
& & $\begin{array}{l}\text { To make sure that the alternative } \\
\text { investment will higher possibility }\end{array}$ \\
Criteria 2 (C2) & The analysis of growth & $\begin{array}{l}\text { To consideration rather in that } \\
\text { investment related to the social- }\end{array}$ \\
& The analysis of social- & political impact. \\
& political impact & To control the pollution when invest to \\
& The analysis of & the alternative which is water \\
priteria 4 (C4) & pollution, land pollution and air \\
& pollution.
\end{tabular}

From the table 3, we can conclude that $C 1$ and $C 4$ based are cost criteria while $C 2$ and $C 3$ are benefit criteria. The HFS decision matrix are given in Table 3.

Table 3: The decision matrix of hesitant fuzzy set

\begin{tabular}{ccccc}
\hline & $C 1$ & $C 2$ & $C 3$ & $C 4$ \\
\hline$A 1$ & $\{0.2,0.4,0.5\}$ & $\{0.6,0.8\}$ & $\{0.2,0.3\}$ & $\{0.3,0.4\}$ \\
$A 2$ & $\{0.2,0.3\}$ & $\{0.3,0.5\}$ & $\{0.5\}$ & $\{0.5,0.6\}$ \\
$A 3$ & $\{0.3,0.4,0.5\}$ & $\{0.2,0.5,0.6\}$ & $\{0.6,0.7\}$ & $\{0.1\}$ \\
$A 4$ & $\{0.7,0.9\}$ & $\{0.2,0.4,0.5\}$ & $\{0.1\}$ & $\{0.5,0.6,0.7\}$ \\
$A 5$ & $\{0.6,0.7,1\}$ & $\{0.3,0.4\}$ & $\{0.1,0.2\}$ & $\{0.7,1\}$ \\
\hline
\end{tabular}

In Table 4, we show the arithmetic mean score function matrix. Table 5 and 6 , shows that PIS, NIS and the ranking for each alternative respectively.

Table 4: Arithmetic-mean score function matrix

\begin{tabular}{ccccc}
\hline & $C 1$ & $C 2$ & $C 3$ & $C 4$ \\
\hline$A 1$ & 0.367 & 0.700 & 0.250 & 0.350 \\
$A 2$ & 0.250 & 0.400 & 0.500 & 0.550 \\
$A 3$ & 0.400 & 0.433 & 0.650 & 0.100 \\
$A 4$ & 0.800 & 0.367 & 0.100 & 0.600 \\
$A 5$ & 0.767 & 0.350 & 0.150 & 0.850 \\
\hline \multicolumn{5}{c}{ Table 5: PIS and NIS for alternatives } \\
\hline$s\left(\tilde{h}_{j}\right)^{+}$ & $C 1$ & $C 2$ & $C 3$ & $C 4$ \\
$s\left(\tilde{h}_{j}\right)^{-}$ & 0.367 & 0.700 & 0.250 & 0.350 \\
\hline
\end{tabular}


INTERNATIONAL JOURNAL OF ACADEMIC RESEARCH IN ACCOUNTING, FINANCE AND MANAGEMENT SCIENCES

Vol. 11, No. 2, 2021, E-ISSN: 2225-8329 @ 2021 HRMARS

Table 6: Ranking of alternatives

\begin{tabular}{ccc}
\hline alternatives & $D$ & Rank \\
\hline$A 1$ & 0.763 & 2 \\
$A 2$ & 0.745 & 3 \\
$A 3$ & 1.016 & 1 \\
$A 4$ & 0.251 & 4 \\
$A 5$ & 0.060 & 5 \\
\hline
\end{tabular}

As we can see from Table 6, the ranking is $A 3 \succ A 1 \succ A 2 \succ A 4 \succ A 5$. The investor should choose computer company for investment. Table 7 show the ranking of Beg and Rashid (2017) and the proposed TOPSIS with different distance score method.

Table 7. The ranking by different methods.

\begin{tabular}{|c|c|c|c|c|c|}
\hline \multirow{2}{*}{$\begin{array}{l}\stackrel{0}{\perp} \\
\frac{1}{0} \\
\frac{5}{0} \\
\frac{ \pm}{4}\end{array}$} & \multirow{2}{*}{ 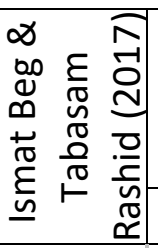 } & \multicolumn{4}{|c|}{ TOPSIS with distance score method } \\
\hline & & $S_{A M}$ & $s_{G M}$ & $s_{p}$ & $s_{F}$ \\
\hline$A 1$ & 2 & 2 & 2 & 1 & 2 \\
\hline$A 2$ & 3 & 3 & 3 & 3 & 3 \\
\hline$A 3$ & 1 & 1 & 1 & 2 & 1 \\
\hline A4 & 4 & 4 & 4 & 4 & 4 \\
\hline A5 & 5 & 5 & 5 & 5 & 5 \\
\hline
\end{tabular}

\section{Conclusion and Future Research}

Through the applications of Investment selection, it has been shown that this approach is both faster and more effective in real-world scenarios. The proposed method effectively avoids the issue of processing data with equal length when determining measure of hesitant fuzzy sets.

Future research should incorporate HFE measurement techniques such as distance and similarity measurements, cross-entropy, and correlation. This way, a variety of problem-solving methods and techniques for MCDM can be introduced.

The second proposal is to conduct an MCDM solution process beginning with the collection of information on the criteria to be used, the respondents' questions and answers, and the order of ranking, and ending with a decision. This will increase the transparency of the MCDM's decisionmaking process.

\section{References}

Beg, I., \& Rashid, T. (2016). Ideal solutions for hesitant fuzzy soft sets. Journal of Intelligent and Fuzzy Systems 30(1): 143-150. doi:10.3233/IFS-151740

Beg, I. \& Rashid, T. (2017). Modelling Uncertainties in Multi-Criteria Decision Making using Distance Measure and TOPSIS for Hesitant Fuzzy Sets. Journal of Artificial Intelligence and Soft Computing Research 7(2): 103-109. doi:10.1515/jaiscr-2017-0007

Ece, O., \& Uludag, A. S. (2017). Applicability of Fuzzy TOPSIS Method in Optimal Portfolio Selection and an Application in BIST. International Journal of Economics and Finance 9(10): 107. 
INTERNATIONAL JOURNAL OF ACADEMIC RESEARCH IN ACCOUNTING, FINANCE AND

MANAGEMENT SCIENCES

Vol. 11, No. 2, 2021, E-ISSN: 2225-8329 @ 2021 HRMARS

doi:10.5539/ijef.v9n10p107

Farhadinia, B. (2014). A series of score functions for hesitant fuzzy sets. Information Sciences 277 : 102-110. doi:10.1016/j.ins.2014.02.009

Garmendia, L., González del Campo, R., \& Recasens, J. (2017). Partial orderings for hesitant fuzzy sets. International Journal of Approximate Reasoning 84: 159-167. doi:10.1016/j.ijar.2017.02.008

Huang, Y., \& Jiang, W. (2018). Extension of TOPSIS Method and its Application in Investment. Arabian Journal for Science and Engineering 43(2): 693-705. doi:10.1007/s13369-017-2736-3

Hwang, C.-L., \& Yoon, K. (1981). Multiple Attribute Decision Making - Methods and Applications. doi:10.1007/978-3-642-45511-7

Mishra, A. R., Rani, P., \& Pardasani, K. R. (2019). Multiple-criteria decision-making for service quality selection based on Shapley COPRAS method under hesitant fuzzy sets. Granular Computing 4(3): 435-449. doi:10.1007/s41066-018-0103-8

Moayyed, F. M., Semiari, M., Hamzeloei, S., \& Semiari, M. (2019). Identifying the Factors Affecting Manufacturing Investment Projects and Using TOPSIS Method for Prioritizing Projects 3(12): 5161.

Ozyesil, M. (2019). An Application of TOPSIS Method for Financial Decision Making Process : A Research on Real Estate Investment Trusts Listed in Borsa Istanbul AN APPLICATION OF TOPSIS METHOD FOR FINANCIAL DECISION MAKING PROCESS: A RESEARCH ON REAL ESTATE INVESTMENT TRUST. Journal of International Trade, Logistics and Law 5(2): 70-80.

Rodzi, Z., \& Ahmad, A. G. (2020). Fuzzy Parameterized Hesitant Fuzzy Linguistic Term Soft Sets ( FPHFLTSSs ) in Multi-Criteria Decision Making. International Journal of Innovative Technology and Exploring Engineering (IJITEE) 9(5): 909-916. doi:10.35940/ijitee.E2519.039520

Torra, V. (2010). Hesitant Fuzzy Sets. international Journal of Intelligent system 25: 529-539. doi:10.1002/int

Torra, V., \& Narukawa, Y. (2009). On hesitant fuzzy sets and decision. IEEE International Conference on Fuzzy Systems 1378-1382. doi:10.1109/FUZZY.2009.5276884

Xia, M., \& Xu, Z. (2011). Hesitant fuzzy information aggregation in decision making. International Journal of Approximate Reasoning 52(3): 395-407. doi:10.1016/j.ijar.2010.09.002

Xu, Z., \& Xia, M. (2011). Distance and similarity measures for hesitant fuzzy sets. Information Sciences 181(11): 2128-2138. doi:10.1016/j.ins.2011.01.028

Xu, Z., \& Zhang, X. (2015). Erratum: Hesitant fuzzy multi-attribute decision making based on TOPSIS with incomplete weight information (Knowledge-Based Systems (2013) 52 (53-64)). KnowledgeBased Systems 77: 128. doi:10.1016/j.knosys.2015.01.012 